\title{
Progress, tradition and history in times of crisis
}

The notion of progress-one of the theoretical bases underpinning constitutive modernityincludes a linear perception of time that makes sense of history and primes us regarding the future. This progress, in turn, presupposes the fundamental unity of humanity, which is assumed to be evolving in the same direction. However, the metaphysics of an idea of progress that holds out the promise of improving the human condition contrasts hugely with the current destructive and annihilating reality, featured by armed conflicts, severe economic crises, global warming, world hunger, globalized terror and the steady depletion of key natural resources.

The ninth thesis of Walter Benjamin's Theses on the Philosophy of History refers to an angel of history, who, contemplating the ruins of history, is caught up in a hurricane of progress built on the ashes of humanity, while advancing towards an uncertain future that holds no hope. Benjamin's fears regarding modernity were undoubtedly grounded in progress, which, in the desire to delete the past in favour of the future, eliminates humanity itself. Offsetting the desolation of the angel of history, however, is human action as a massive rebellious force.

Optimism regarding the development of science and technology led theoreticians like Francis Bacon to affirm that the role of humankind was simply to control nature by understanding its laws. This optimism linked with the notion of progress was thus added to the determination to control nature and expand and grow in economic terms. While allowing for the possibility of accumulating scientific knowledge, this same optimism led to the conclusion that modernity was superior to antiquity and that certain civilizations were superior to others-with all the consequences that this implied.

Tradition became an obstacle and the hurdling of this obstacle was propelled by reason. What was new was better simply because it was new; and we aspired to the new because its production was a guarantee of perfection and progress. Thus, progress, the outcome of evolution, was raised as a principle of this same evolution. As far as modern progressives were concerned, anything that raised opposition to progress - tradition, prejudice, etc — had to be rejected, precisely because it prevented the development of the sense of history itself. This idea grew and spread to the point where it transformed humans themselves, who thus associated material progress with moral and human progress. Benjamin's desolate angel of history is there to remind us, however, that the two kinds of progress are not necessarily linked.

Faced with the teleology implicit in the idea of progress, we need to ask ourselves what it is that remains isolated and invisible in the margins of the discourse that presupposes directionality. There is an incapacity to understand the singular coalescence of the localized adaptation of a variant on the history described above because it is associated with the meta-narrative on progress. Against this history we can, however, as suggested by a lucid Friedrich Nietzsche, juxtapose another somewhat inconvenient history as counter-memory—one that accounts for the history 


\section{artnodes 8}

http://artnodes.uoc.edu

of truths, rather than for the truth of history. Like a critical archaeological study, it would reveal how what is presented as new often has nothing of the new in it. By attending to what remains hidden, therefore, we reveal the old in the new and the new in the old.

In these times of harbingered crises, we need to be aware that a past event does not always become immersed and then buried, forgotten, in an immemorial past; rather, this past persists and is renewed in a thousand and one ways. Bearing in mind the contribution, to future science and technology, of the critical component in creativity and the lessons of a disruptive history, taking account of the future and of multiplicity and assessing differences so that the depths of novelty can be explored, is, today, a key strategy to be taken into account in terms of the fragile equilibrium that contrasts renewed optimism with crude reality.

Pau Alsina

Director of Artnodes 